\title{
Quality of life among adult patients with neurofibromatosis 1, neurofibromatosis 2 and schwannomatosis: a systematic review of the literature
}

\section{Citation}

Vranceanu, Ana-Maria, Vanessa L. Merker, Elyse Park, and Scott R. Plotkin. 2013. “Quality of Life Among Adult Patients with Neurofibromatosis 1, Neurofibromatosis 2 and Schwannomatosis: a Systematic Review of the Literature." Journal of Neuro-Oncology 114 (3) (July 2): 257-262. doi:10.1007/s11060-013-1195-2.

\section{Published Version}

doi:10.1007/s11060-013-1195-2

\section{Permanent link}

http://nrs.harvard.edu/urn-3:HUL.InstRepos:33788488

\section{Terms of Use}

This article was downloaded from Harvard University's DASH repository, and is made available under the terms and conditions applicable to Other Posted Material, as set forth at http:// nrs.harvard.edu/urn-3:HUL.InstRepos:dash.current.terms-of-use\#LAA

\section{Share Your Story}

The Harvard community has made this article openly available.

Please share how this access benefits you. Submit a story. 
Quality of life among adult patients with neurofibromatosis 1, neurofibromatosis 2 and schwannomatosis: A systematic review of the literature

Ana-Maria Vranceanu ${ }^{1}$, Vanessa L. Merker², Elyse Park ${ }^{1}$, and Scott R. Plotkin ${ }^{2}$

1. Department of Psychiatry, Massachusetts General Hospital/Harvard Medical School

2. Department of Neurology and Cancer Center, Massachusetts General Hospital/Harvard Medical School

Corresponding Author:

Scott R. Plotkin, MD, Ph.D.

Massachusetts General Hospital

Yawkey 9E

55 Fruit Street

Boston, MA 02114

Phone: 617-726-3650

Fax: 617-643-2591

Email: splotkin@partners.org 


\begin{abstract}
:
The aim of this study was to review the literature on quality of life among adult patients with neurofibromatosis 1 , neurofibromatosis 2 and schwannomatosis, and to identify the specific aspects of quality of life that were studied and reported in this population. We also set out to report predictors of quality of life. Published research reports were included if they described quality of life in this population and met methodological quality according to a list of predefined criteria. Eight studies (7 in NF1, 1 in NF2, 0 in schwannomatosis), conducted between 2001 and 2013, met inclusion criteria. The methodological quality of the 8 studies was mostly high according to ratings by predefined criteria. Most studies reported that patients with NF experience decreased quality of life when compared to the general population. Visibility and disease severity were strong predictors of skin-specific quality of life in NF1 patients. However, the majority of findings regarding predictors of quality of life were weak or inconclusive. Given the decreased quality of life in NF patients, it is important to examine more comprehensively the psychosocial factors in this population, especially in patients with NF2 and schwannomatosis.

Mind body interventions that address these domains may provide comprehensive and efficacious long term treatment.
\end{abstract}

Key Words: neurofibromatosis 1, neurofibromatosis 2, schwannomatosis, quality of life, 


\section{Introduction}

The neurofibromatoses (neurofibromatosis 1, neurofibromatosis 2 and schwannomatosis) are a group of genetic disorders that predispose patients to develop multiple nerve sheath tumors throughout the body. NF1 is the most common neurogenetic disorder, with an estimated birth incidence of 1:2700 [1]. Symptoms of NF1 include cutaneous manifestation, such as cafe-au-lait macules and cutaneous neurofibromas; bony abnormalities, such as pseudoarthrosis and scoliosis; learning disabilities; and gliomas [2]. NF2 is less common with an estimated birth incidence of 1:33,000 [1] and is characterized by the presence of bilateral vestibular schwannomas, which can lead to deafness, tinnitus, and balance problems [3]. Many patients with NF2 also have other tumors of the central nervous system such as meningiomas and spinal ependymomas.. Schwannomatosis likely has a prevalence similar to that of NF2 [4] and is characterized by the development of multiple schwannomas that may cause intractable pain [3].

Within the past decade, there has been increased awareness of the burden of disease in this population. While most NF-related tumors are histologically benign, each disorder can cause a significant decrease in quality of life in affected individuals.

The neurofibromatoses are heterogeneous diseases. Some individuals with NF1 live essentially normal lives, while others struggle with cosmetic disfigurement, neurologic dysfunction, psychological distress, and disability. [ 5, 6] Similarly, some patients with NF2 have life threatening symptoms from compression of vital structures, such as other cranial nerves and the brain stem, while others have more minor symptoms. In schwannomatosis, most individuals report pain, but only some develop pain-related disability. This heterogeneity of these diseases highlights the importance of identifying predictors of quality of life in this population. Quality of 
life represents individuals' perception of their general well being, and typically includes emotional and physical components.

Within the past decade there has been an increased awareness of the mind-body connection in quality of life in patients with medical conditions, leading to a transition from a biomedical to a biopsychosocial model of care, where the medical and psychosocial factors of disease are assessed and treated concurrently. Although treatments for NF continue to be largely biomedical, research has started to assess quality of life in this population, as well as predictors of quality of life. The goals of this review were: 1) to identify the specific aspects of quality of life that are adversely affected in this population and have been reported in the research literature, and 2) to identify predictors of quality of life in this population. We were also interested in providing directions for future research, in particular with regard to the development of mind-body interventions and transitioning of care from a biomedical to biopsychosocial model of care.

\section{Methods}

We followed the PRISMA criteria [5] to identify, select, and determine eligibility of studies for inclusion in this systematic review.

\section{Search strategy/identification}

Reports of original research studies on the QoL of adults affected with NF1, NF2, or schwannomatosis were identified. Articles published in peer-reviewed journals as of February 27, 2013, were identified using literature searches of Pubmed and PsychINFO. Database searches were conducted using the terms neurofibromatosis, schwannomatosis, NF1, and NF2 in conjunction with one or more of the following key terms: quality of life, QoL, health related 
quality of life, and well being. A total of 111 articles were identified, and after removing duplicates, the abstracts of 101 articles were screened.

\section{Selection Criteria/Study Eligibility}

Detailed inclusion and exclusion criteria were defined by the authors prior to reviewing abstracts (see Table 1). Eighty-eight studies did not meet inclusion criteria. Of these, 13 studies did not address individuals with NF, 48 did not address quality of life (29 reported only biomedical characteristics, 9 used cognitive/functional scales only, and 10 reported other findings), 16 addressed children only, 10 were case studies/or qualitative reports, and 2 were not in English. A total of 12 abstracts met inclusion criteria and the full-text was assessed further for eligibility. Four studies that did not measure quality of life with a standardized, reliable, and valid questionnaire were excluded, leaving 8 studies for inclusion in the review.

\section{Data Extraction/Quality Assessment}

Two investigators (A-M. V. and V.L.M) extracted data from the selected studies. Information was extracted on: study population, study design, QoL instrument, results, and key predictor variables. These authors then assessed the methodological quality of each study using a standardized 10-item checklist of predetermined criteria (Table 2). The checklist was a modified population-specific version of a previously established criteria list for systematic reviews [6,7]. Evaluation of the methodological quality yielded over $90 \%$ agreement between the two reviewers; all disagreements were resolved upon discussion.

Each item of a selected study that met our criteria was assigned one point. If an item did not meet our criteria or was described insufficiently, zero points were assigned. The highest possible score was 10 . Studies scoring $70 \%$ or more of the maximum attainable score (e.g., score $\geq 7$ ) were arbitrarily considered to be of "high quality". Studies scoring between 50\%-70\% 
were rated as "moderate quality" (score 5-7). Studies scoring lower than $50 \%$ were considered "low quality" (score $\leq 4$ ). Findings regarding predictors of quality of life were summarized according to level of evidence [8], (Table 3) and considered consistent if $\geq 70 \%$ of the studies that investigated a factor showed the same direction of the association.

\section{Results}

Study characteristics

A total of 8 studies were included [9-16]. All were cross-sectional surveys published between 2001-2013. Studies were conducted in variety of countries ( 2 in the US, 2 in Germany, 1 each in Belgium, the UK, Italy, and France). Of the 8 studies, 7 included patients with NF1, 1 included patients with NF2, and none included patients with schwannomatosis. These studies included a total of 1045 patients with NF1, 62 patients with NF2, and 30 healthy controls. Table 3 presents a summary of the studies' characteristics and findings, as well as their quality scores. The mean quality score for the studies was 7.1. Methodological shortcomings concerned mainly the lack of reported response rate and information on non-responders.

\section{QoL measures}

The validated instruments used to measure $\mathrm{QoL}$ in these studies can be categorized as general measures and diseases specific measures. The Medical Outcome Scale SF-36 is a 36item scale is a general measure, constructed to survey general quality of life [17]. The SF-36 assesses eight health concepts: limitations in physical activities because of health problems; limitations in social activities because of physical or emotional problems; limitations in usual role activities because of physical health problems); bodily pain; general mental health (psychological distress and well-being); limitations in usual role activities because of emotional 
problems; vitality (energy and fatigue); and general health perceptions. Other less known general QoL measures are: PedsQLNF1 Module-Adult (with physical, emotional, cognitive, and social functioning subscales) and Patient Benefit Questionnaire. The Skindex [18] is an NF1 disease specific 29 item measure design to determine skin specific quality of life, and it is used primarily in NF1 patients who have facial deformities as a primary marker. The measure has 3 subscales emotion, physical symptoms and functioning. The Dermatology Life Quality Index is a similar diseases specific measure. The Voice Handicap Index is a disease specific QoL measure assessing quality of voice. While the general measures give information on general functioning of a patient, the more specific measures provide a more clear relationship between particular symptoms (usually the more bothersome, like the skin deformities in NF1 patients) and quality of life. QoL findings

Overall patients with NF reported lower general quality of life compared to the general population. The majority of studies used the SF-36 to assess general health-related QoL (e.g., not disease-specific QoL). In all these studies, impairment was found not only in the physical and mental summary scores, but also in the individual subscales suggesting difficulties in most aspects of QoL. Patients with NF1 also reported decreased skin-specific QoL (using the Skindex) compared to the general population. Voice-related quality of life was also found to be significantly lower compared to matched controls in one moderate quality study [11]. NF1 patients treated by specialists had significantly greater enjoyment of life and ability to lead a normal life than those treated by non-NF specialists in another moderate quality study [12]. Predictors of quality of life 
The predictors of quality of life described below are listed in table 5. Strong evidence was found for the predictive value of visibility (cosmetic effects) and disease severity (medical complications and procedures) for skin-specific QoL in NF1 patients. There was strong evidence that neither visibility nor gender predicted general QoL. Weak evidence was found for the relationship between age and skin-specific QoL, with older patients having more impairment. There was also weak evidence for the association between general QoL and difficulties with social communication, communication with spouse/significant other, balance, and hearing patients with NF2. These difficulties were associated with lower QoL on selected subscales of the SF-36. Inconclusive evidence was found for the relationship between age, health status, treatment by a specialist, severity and general QoL, and between gender and skin-specific QoL.

\section{Discussion}

This systematic review summarizes the results of 8 studies on the quality of life of patients affected by NF1 ( 7 studies) and NF2 (1 study). No studies on schwannomatosis met inclusion criteria. All studies reported lower quality of life in patients with NF compared to the general population, regardless of the instrument used. When general QoL was assessed with SF36, impairment was observed on all subscales: physical functioning, role physical, bodily pain, general health, vitality, social functioning, role emotional, and mental health. When a skin disease-specific QoL measure was used, impairment was found on each subscale of emotions, symptoms, and function. These results suggest that NF represents a considerable burden for patients, affecting all aspects of life.

In general, NF1 patients with more severe disease (e.g., medical complications) and visible (e.g., cosmetic effects) symptoms report worse skin specific quality of life. Although 
inconclusive, there was some evidence suggesting that women affected by NF1 may have worse skin disease-specific QoL compared to men with NF1. Contrary to expectations, there was strong evidence that visibility of disease and gender did not predict general QoL. This suggests that perhaps psychosocial and coping factors may buffer the effect of visibility on general QoL.

Patients with NF1 often have visible external tumors that may be cosmetically disfiguring and associated with stigma and social exclusion [19]. As such, NF1 represents an assault on the self-image and lifestyle of patients. Patients may become self conscious and isolated, leading to an array of mental health difficulties. While reducing malformations is a priority in patients with NF1, repeated medical procedures are in of themselves stressful and imperfect, with inherent medical risks. In many situations, the risk of surgical complications outweighs the potential benefits of tumor excision. In the absence of a medical cure, psychosocial mind-body interventions to teach patients how to adjust to their condition are pivotal in improving quality of life in this population. This contention is similar to other chronic conditions for which there is no cure, such as chronic pain. However, more research on the specific psychosocial predictors of quality of life is necessary, as the majority of the findings from this review were weak or inconclusive, and mostly concerning only patients with NF1. Future research should assess psychosocial factors that have been found to be important in reports of QoL in other patients with chronic illness and cancer, such as coping, resiliency, depression, anxiety, and self efficacy [20,21]. If found to be important predictors of QoL, these can areas can become targets of future mind body interventions aimed at improving QoL in this population.

The results described in this review were partly inconclusive, despite use of validated QoL measures in each study. This was due to limited studies and/or poor methodology. Future research in this area should use reference groups of similarly aged individuals without NF and 
reliable and valid QoL instruments. Replication of current studies in order to determine the conclusiveness of some results would also be beneficial to the field. In the meantime, we can implement strategies based on current knowledge about QoL in this population. For example, these studies indicate that severity and visibility are important predictors of skin specific QoL, and that generally women are more impaired in their skin diseases specific QoL. As such, these factors should be routinely assessed and accounted for by clinicians who treat patients with NF, and referrals for psychosocial treatments should be made for appropriate patients. Research on breast cancer shows that psychosocial intervention projects ${ }^{22}$ resulted in both short and long term improved QoL and also decreased health care billings by $24 \%$ compared to women who did not attend these interventions. Future studies should explore whether interventions specifically designed for NF patients could yield similar results.

In sum, this systematic review shows that patients with NF suffer from impaired QoL. There is a relative lack of high quality studies in adult patients with NF, especially in patients with NF2 and schwannomatosis. There is a need for additional high quality research in this population, focused on assessing not only QoL, but also psychosocial predictors of QoL. This would allow development of mind body interventions integrated within biomedical practice, aimed at improving QoL in this population. 


\section{Conflict of interest}

The authors declare that they have no conflict of interest. 


\section{References}

1. Evans DG, Howard E, Giblin C, Clancy T, Spencer H, Huson SM, Lalloo F. (2010) Birth incidence and prevalence of tumor-prone syndromes: estimates from a UK family genetic register service. Am J Med Genet A 152A:327-332.

2. Lu-Emerson C, Plotkin SR. (2009) The Neurofibromatoses. Part 1: NF1. Rev Neurol Dis 6:E47-E53.

3. Lu-Emerson C, Plotkin SR. (2009) The neurofibromatoses. Part 2: NF2 and schwannomatosis. Rev Neurol Dis 6:E81-E86.

4. Antinheimo J, Sankila R, Carpen O, Pukkala E, Sainio M, Jaaskelainen J. (2000) Populationbased analysis of sporadic and type 2 neurofibromatosis-associated meningiomas and schwannomas. Neurology 54:71-76.

5. Moher D, Liberati A, Tetzlaff J, Altman DG. (2009) Preferred reporting items for systematic reviews and meta-analyses: the PRISMA statement. PLoS Med 6:e1000097-

6. Kuijpers T, van der Windt DA, van der Heijden GJ, Bouter LM. (2004) Systematic review of prognostic cohort studies on shoulder disorders. Pain 109:420-431.

7. Scholten-Peeters GG, Verhagen AP, Bekkering GE, van der Windt DA, Barnsley L, Oostendorp RA, Hendriks EJ. (2003) Prognostic factors of whiplash-associated disorders: a systematic review of prospective cohort studies. Pain 104:303-322.

8. Ariens GA, van MW, Bongers PM, Bouter LM, van der Wal G. (2000) Physical risk factors for neck pain. Scand J Work Environ Health 26:7-19.

9. Wolkenstein P, Zeller J, Revuz J, Ecosse E, Leplege A. (2001) Quality-of-life impairment in neurofibromatosis type 1: a cross-sectional study of 128 cases. Arch Dermatol 137:1421-1425.

10. Granstrom S, Langenbruch A, Augustin M, Mautner VF. (2012) Psychological burden in adult neurofibromatosis type 1 patients: impact of disease visibility on body image. Dermatology 224:160-167.

11. Cosyns M, Mortier G, Janssens S, Van BJ. (2012) Voice-related quality of life in adults with neurofibromatosis type 1. J Voice 26:e57-e62.

12. Langenbruch AK, Augustin M, Granstrom S, Kluwe L, Mautner VF. (2011) Clinical and healthcare status of patients with neurofibromatosis type 1. Br J Dermatol 165:225-227.

13. Neary WJ, Hillier VF, Flute T, Stephens SD, Ramsden RT, Evans DG. (2010) The relationship between patients' perception of the effects of neurofibromatosis type 2 and the domains of the Short Form-36. Clin Otolaryngol 35:291-299. 
14. Kodra Y, Giustini S, Divona L, Porciello R, Calviei S, Wolkenstein P, Taruscio D. (2009) Health-Related Quality of Life in Patients with Neurofibromatosis Type 1. Dermatology 218:215-220.

15. Page PZ, Page GP, Ecosse E, Korf BR, Leplege A, Wolkenstein P. (2006) Impact of Neurofibromatosis 1 on Quality of Life: A Cross-Sectional Study of 176 American Cases. Am J Med Genet A 140A:1893-1898.

16. Nutakki K, Hingtgen CM, Monahan P, Varni JW, Swigonski NL. (2013)

Development of the Adult PedsQL Neurofibromatosis Type 1 Module: Initial Feasibility, Reliability and Validity. Health Qual Life Outcomes 11:21-

17. Ware JE, Jr., Sherbourne CD. (1992) The MOS 36-item short-form health survey (SF-36). I. Conceptual framework and item selection. Med Care 30:473-483.

18. Chren MM, Lasek RJ, Flocke SA, Zyzanski SJ. (1997) Improved discriminative and evaluative capability of a refined version of Skindex, a quality-of-life instrument for patients with skin diseases. Arch Dermatol 133:1433-1440.

19. Samuelsson B, Riccardi VM. (1989) Neurofibromatosis in Gothenburg, Sweden. III. Psychiatric and social aspects. Neurofibromatosis 2:84-106.

20. Bull AA, Meyerowitz BE, Hart S, Mosconi P, Apolone G, Liberati A. (1999) Quality of life in women with recurrent breast cancer. Breast Cancer Res Treat 54:47-57.

21. Downe-Wamboldt B, Butler L, Coulter L. (2006) The relationship between meaning of illness, social support, coping strategies, and quality of life for lung cancer patients and their family members. Cancer Nurs 29:111-119.

22 Carslon LE, , Bultz BD. (2004) Efficacy and medical cost offset of psychosocial internventions in cancer care: Making the case of economic analyses. Psychooncology 13:837-347. 
Table 1 Selection Criteria

\begin{tabular}{l|l}
\hline Inclusion Criteria & Exclusion Criteria \\
\hline Original research in peer-reviewed journal & Biomedical description only \\
Study population of patients with NF1, & Cognitive/emotional scales only \\
NF2, and/or schwannomatosis & \\
Includes adults (age 18+) & Qualitative study or case report \\
Use of a standardized, validated QoL & Article not available in English \\
measure & \\
\hline
\end{tabular}


Table 2. Criteria for assessing methodological quality of studies included in this review.

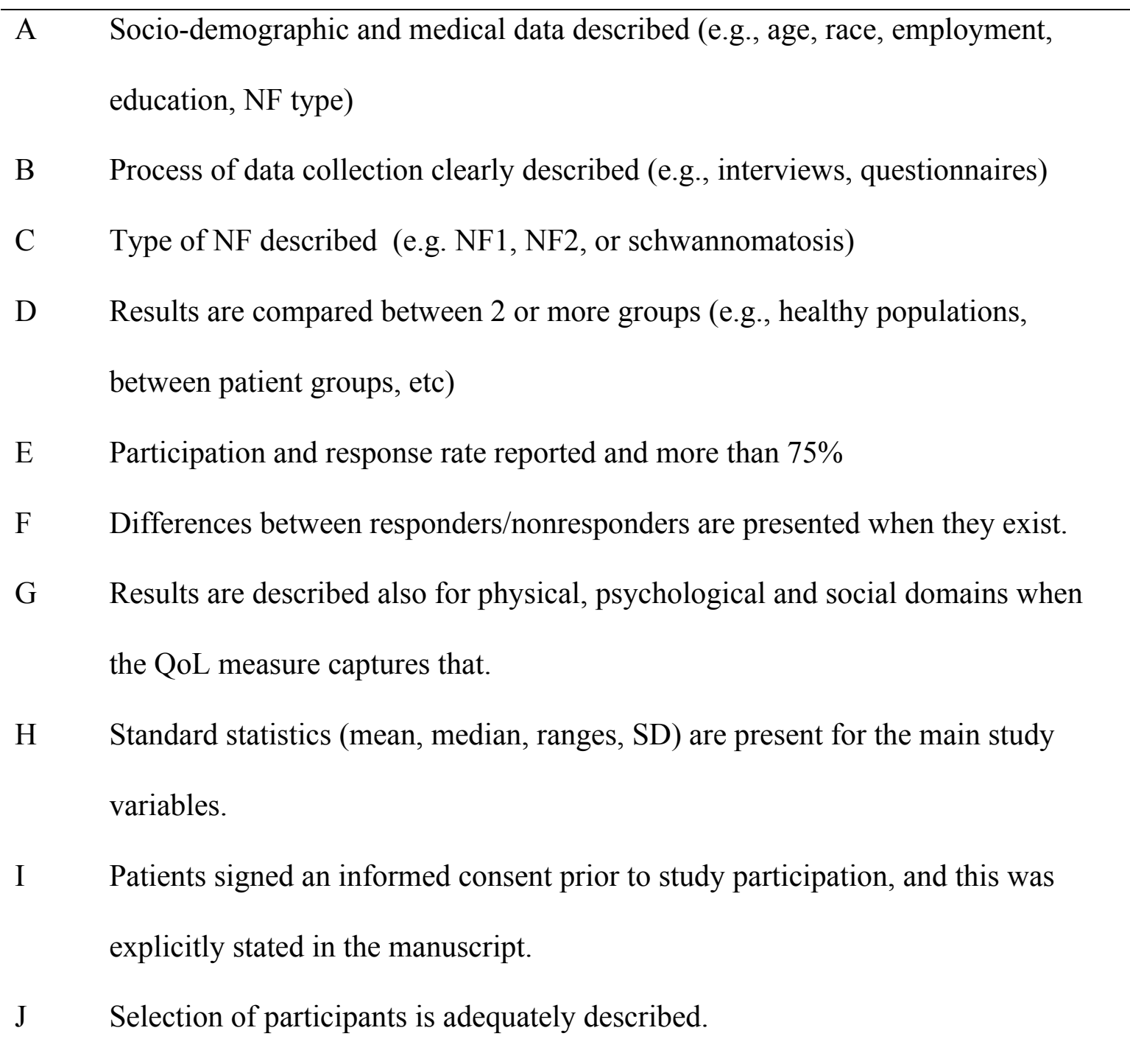


Table 3. Level of evidence (adapted from Ariens et al, 2000)

\begin{tabular}{ll}
\hline Strong & Consistent findings $(\geq 70 \%)$ in at least 2 high quality studies \\
Moderate & Consistent findings $(\geq 70 \%)$ in one quality study and at least one \\
& moderate or low quality study \\
Weak & Findings in one high quality study or consistent findings $(\geq 70 \%)$ in at \\
& least 3 or more low quality studies \\
Inconclusive & Inconsistent findings, or less than 3 low quality studies available \\
No evidence & No data present
\end{tabular}


Table 4. Overview of studies on quality of life among patients with NF1, NF2 and Schwannomatosis

\begin{tabular}{|c|c|c|c|c|c|}
\hline Study & $\begin{array}{l}\text { Study } \\
\text { quality } \\
\text { score }\end{array}$ & Participants & $\begin{array}{l}\text { Age } \\
\text { Mean } \\
\text { (SD) }\end{array}$ & $\begin{array}{l}\text { QoL } \\
\text { measure }\end{array}$ & $\begin{array}{l}\text { General } \\
\text { Conclusion }\end{array}$ \\
\hline $\begin{array}{l}\text { Wolkenstein } \\
\text { et al, 2001[9] }\end{array}$ & 10 & $\begin{array}{l}128 \text { adults } \\
\text { with NF1 }\end{array}$ & $\begin{array}{l}40.4 \\
(14.1)\end{array}$ & $\begin{array}{l}\text { SF-36; } \\
\text { Skindex }\end{array}$ & $\begin{array}{l}\text { Patients with NF have lower scores on the SF-36 compared to } \\
\text { normal population. Severity of NF1 significantly predicted scores } \\
\text { on SF-36 domains of physical functioning, bodily pain, general } \\
\text { health perception and vitality but no Skindex domains. Visibility of } \\
\text { NF1 significantly predicted lower scores on all subscales of the } \\
\text { Skindex and on SF-36 domains of physical functioning, role- } \\
\text { physical, social functioning, role-emotional, and mental health. }\end{array}$ \\
\hline $\begin{array}{l}\text { Kodra et al, } \\
2009[14]\end{array}$ & 10 & $\begin{array}{l}129 \text { adults } \\
\text { with NF1 }\end{array}$ & $\begin{array}{l}37.7 \\
(12.2)\end{array}$ & $\begin{array}{l}\text { SF-36; } \\
\text { Skindex }\end{array}$ & $\begin{array}{l}\text { NF1 patients had significantly lower scores on all SF-36 domains } \\
\text { compared to general population. Increased visibility was } \\
\text { significantly associated with all subscales of the Skindex but none } \\
\text { of the SF-36. }\end{array}$ \\
\hline
\end{tabular}




\begin{tabular}{|c|c|c|c|c|c|}
\hline $\begin{array}{l}\text { Page et al, } \\
2006[15]\end{array}$ & 9 & $\begin{array}{l}169 \text { adults } \\
\text { with NF1 }\end{array}$ & $\begin{array}{l}43 \\
(11.7)\end{array}$ & $\begin{array}{l}\text { SF-36; } \\
\text { Skindex }\end{array}$ & $\begin{array}{l}\text { NF1 patients had significantly lower scores on all SF-36 domains } \\
\text { compared to general population, with larger effects in patients with } \\
\text { more severe complications. Increased disease visibility correlated } \\
\text { with lower QoL as measured by the Skindex but not the SF-36. } \\
\text { Increased disease severity was associated with worse scores on the } \\
\text { physical functioning and symptom subscales of the Skindex and all } \\
\text { subscales of the SF-36. }\end{array}$ \\
\hline $\begin{array}{l}\text { Neary et al, } \\
2010[13]\end{array}$ & 9 & $\begin{array}{l}62 \text { adults } \\
\text { with NF2 }\end{array}$ & $\begin{array}{l}39.8 \\
(15.1)\end{array}$ & SF-36 & $\begin{array}{l}\text { NF2 patients had significantly lower scores on all subscales of the } \\
\text { SF-36 compared to the general population. Significant correlations } \\
\text { between all SF-36 subscales and patients' perceptions of difficulties } \\
\text { with social communication and balance; selected subscales } \\
\text { correlated with communicating with spouse/significant other, } \\
\text { hearing difficulties, and mood change. }\end{array}$ \\
\hline $\begin{array}{l}\text { Langenbruch } \\
\text { et al, }\end{array}$ & 6 & $\begin{array}{l}228 \text { adults } \\
\text { with NF1 }\end{array}$ & $\begin{array}{l}44 \\
(13)\end{array}$ & $\begin{array}{l}\text { Patient } \\
\text { Benefit }\end{array}$ & $\begin{array}{l}\text { NF1 patients treated by specialists had significantly greater } \\
\text { enjoyment of life and ability to lead a normal life than those treated }\end{array}$ \\
\hline
\end{tabular}




\begin{tabular}{|c|c|c|c|c|c|}
\hline $2011[12]$ & & & & Questionnaire & by non-NF specialists. \\
\hline $\begin{array}{l}\text { Granstrom et } \\
\text { al, 2012[10] }\end{array}$ & 5 & $\begin{array}{l}228 \text { adults } \\
\text { with NF1 }\end{array}$ & $\begin{array}{l}43.8 \\
(13.3)\end{array}$ & $\begin{array}{l}\text { Dermatology } \\
\text { Life Quality } \\
\text { Index }\end{array}$ & $\begin{array}{l}\text { Higher self-perceived disease visibility was significantly associated } \\
\text { with decreased QoL. Body image (as measured by the } \\
\text { insecurity/experience subscale of the Evaluation of the Own Body } \\
\text { Questionnaire) partly mediated the effect of visibility on quality of } \\
\text { life. }\end{array}$ \\
\hline $\begin{array}{l}\text { Cosyns et al, } \\
2012[11]\end{array}$ & 5 & $\begin{array}{l}29 \text { adults } \\
\text { with NF1, } \\
30 \text { healthy } \\
\text { controls }\end{array}$ & $\begin{array}{l}35 \\
(10.9)\end{array}$ & $\begin{array}{l}\text { Voice } \\
\text { Handicap } \\
\text { Index (VHI) }\end{array}$ & $\begin{array}{l}\text { NF patients had significantly worse scores on the VHI compared to } \\
\text { matched healthy controls. Voice quality, as measured by the } \\
\text { Dysphonia Severity Index, did not correlate with VHI, but } \\
\text { increased age predicted worse voice-related quality of life. }\end{array}$ \\
\hline $\begin{array}{l}\text { Nutakkiet al, } \\
2013[16]\end{array}$ & 5 & $\begin{array}{l}134 \text { adults } \\
\text { with NF1 }\end{array}$ & 40.2 & $\begin{array}{l}\text { PedsQLNF1 } \\
\text { Module-Adult }\end{array}$ & $\begin{array}{l}\text { Quality of life (including physical, emotional, cognitive, and social } \\
\text { functioning subscales) significantly decreases as self-reported } \\
\text { health status declines. }\end{array}$ \\
\hline
\end{tabular}


Vranceanu et al.

Table 5. Predictors of QOL in NF1

\begin{tabular}{|c|c|c|c|c|}
\hline Possible predictor & $\begin{array}{l}\text { Direction of } \\
\text { Association }\end{array}$ & $\begin{array}{l}\text { Strong } \\
\text { evidence }\end{array}$ & $\begin{array}{l}\text { Weak } \\
\text { evidence }\end{array}$ & Inconclusive \\
\hline \multicolumn{5}{|l|}{ NF1 } \\
\hline \multicolumn{5}{|l|}{ General QoL } \\
\hline Visibility $^{16,17}$ & No association & $\mathrm{X}$ & & \\
\hline Gender $^{16,17}$ & No association & $\mathrm{X}$ & & \\
\hline Severity $^{11,17}$ & Negative & & & $\mathrm{X}$ \\
\hline Health status $^{18}$ & Positive & & & $X$ \\
\hline Age $^{11,16,17}$ & No consensus & & & $\mathrm{X}$ \\
\hline \multicolumn{5}{|l|}{ Skin-specific QoL } \\
\hline Visibility $^{11,12,16,17}$ & Negative & $\mathrm{X}$ & & \\
\hline Severity $^{11,17}$ & Negative & $\mathrm{X}$ & & \\
\hline Age ${ }^{16,17}$ & Negative & & $\mathrm{X}$ & \\
\hline Gender $^{11,16}$ & No consensus & & & $\mathrm{X}$ \\
\hline \multicolumn{5}{|l|}{ Other QoL measures } \\
\hline $\begin{array}{l}\text { Severity and voice related } \\
\text { QoL }^{13}\end{array}$ & Negative & & & $\mathrm{X}$ \\
\hline $\begin{array}{l}\text { Treatment by a specialist } \\
\text { and life enjoyment }{ }^{14}\end{array}$ & Positive & & & $\mathrm{X}$ \\
\hline \multicolumn{5}{|l|}{ NF2 } \\
\hline \multicolumn{5}{|l|}{ General QoL } \\
\hline $\begin{array}{l}\text { Difficulties with social } \\
\text { communication }^{15}\end{array}$ & Negative & & $X$ & \\
\hline $\begin{array}{l}\text { Communicating with } \\
\text { spouse/significant other }{ }^{15}\end{array}$ & Negative & & $X$ & \\
\hline Balance $^{15}$ & Negative & & $\mathrm{X}$ & \\
\hline Hearing difficulties $^{15}$ & Negative & & $\mathrm{X}$ & \\
\hline Mood change $^{15}$ & Negative & & $\mathrm{X}$ & \\
\hline
\end{tabular}


Supplemental Figure: Prisma 2009 Flow diagram
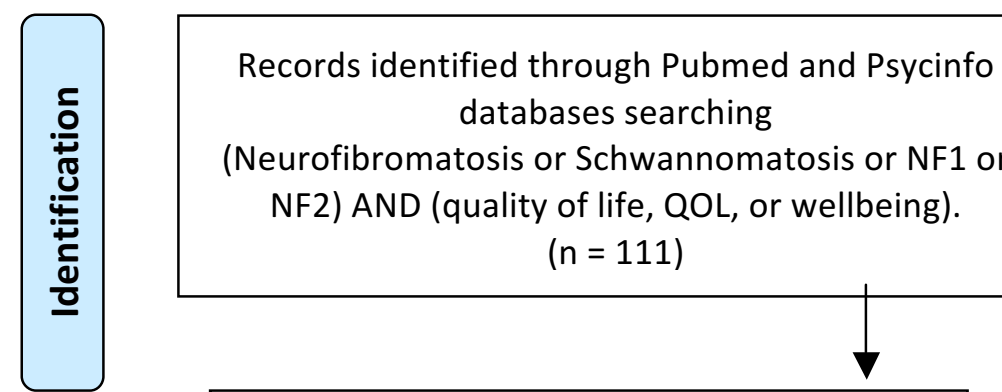

(Neurofibromatosis or Schwannomatosis or NF1 or NF2) AND (quality of life, QOL, or wellbeing).
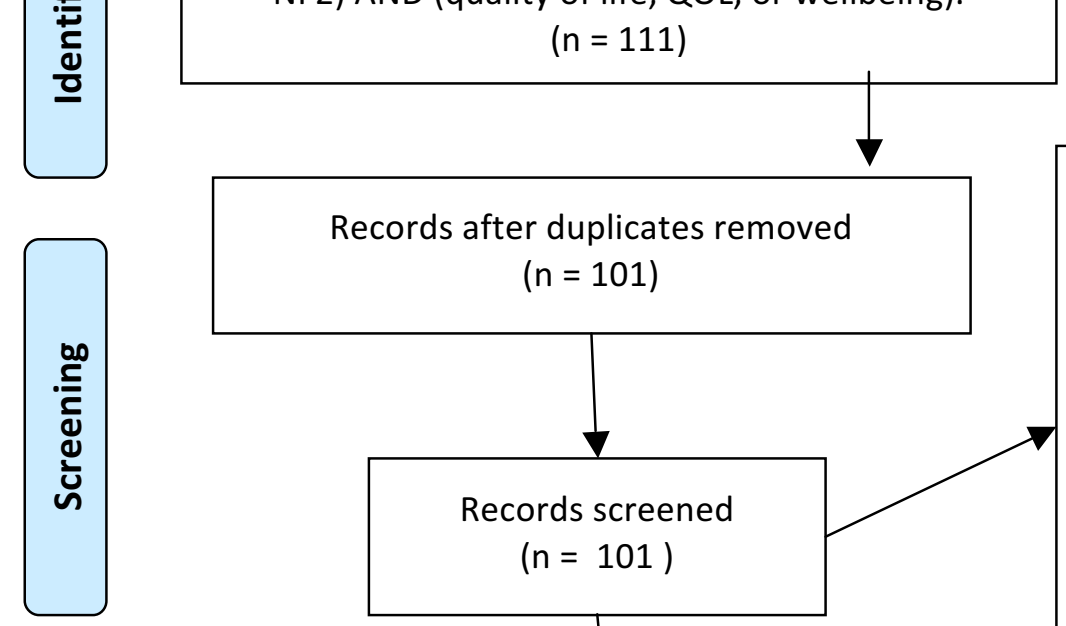

Records after duplicates removed

$$
(n=101)
$$

Not NF: 13

Not QOL: Functional/cognitive scales only - 9, Biomedical - 29,

Not adults - 16

Case studies/qualitative -10 ,

Article not in English - 2,

Other - 10
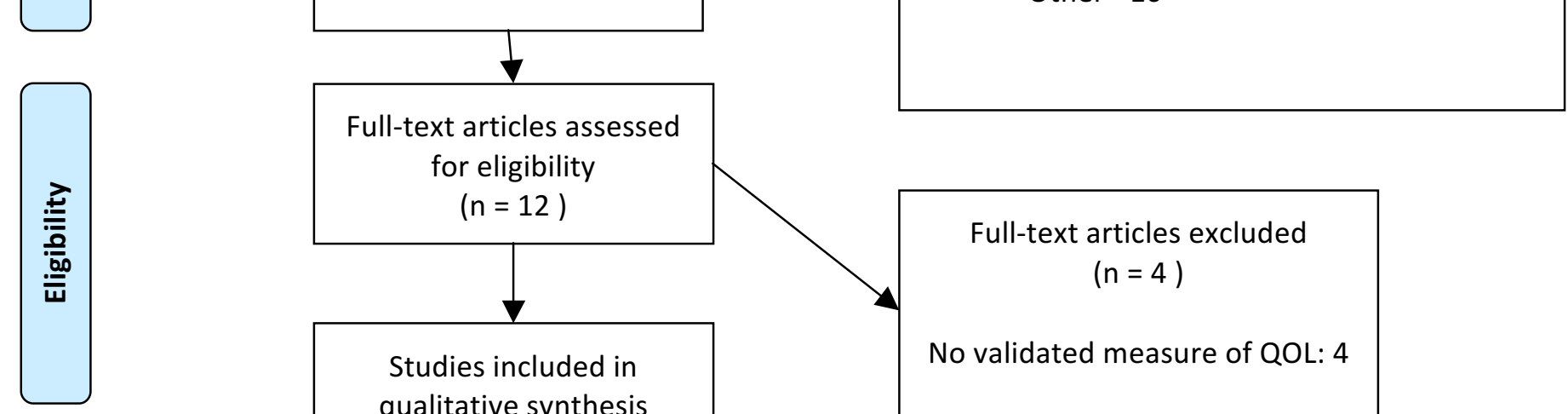

Full-text articles assessed for eligibility $(n=12)$

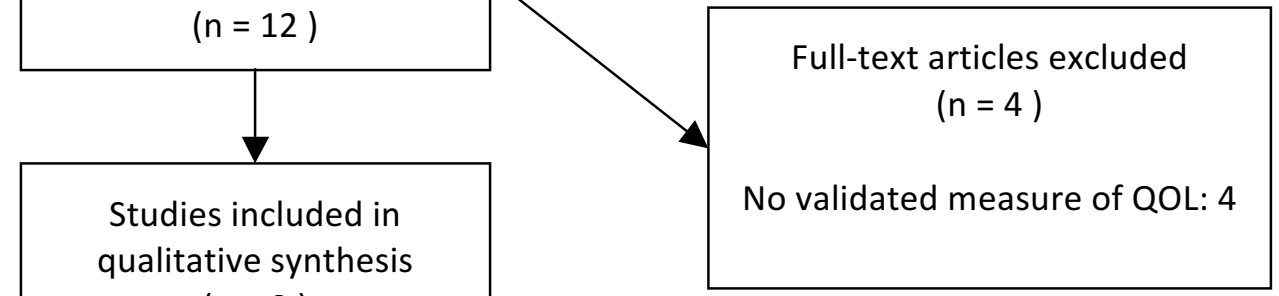

Assess level of quality based on checklist 